
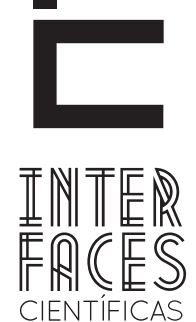

DIREITO

\title{
INTERRUPÇ̃̃O DE GRAVIDEZ DE FETO ANENCÉFALO E A ADPF 54: AVANÇO OU RETROCESSO?
}

Caroline Leite de Camargo ${ }^{1}$

\section{RESUMO}

O Brasil é o quarto país no mundo em casos de fetos anencéfalos, o que fez com que a questão chegasse até o órgão máximo do judiciário brasileiro e em 12 de abril de 2012 foi decidido que a gestante tem a liberdade de interromper ou não a gestação. Tal decisão se mostra inovadora e veio a fim de sanar problemas antigos de violação referente à dignidade da mulher. Entretanto, tal medida poderá acarretar sérios problemas, tendo em vista que a intervenção do poder judiciário no atuar do poder executivo pode ocasionar violação de direitos, uma vez que o Poder Público nem sempre terá meios para propiciar às gestantes tratamentos médicos e psicológicos antes, durante e depois da interrupção da gravidez. Ressalte-se ainda que nem todos os centros de saúde estarão aptos a realizarem a interrupção da gravidez de fetos anencéfalos nem haverá profissionais qualificados para tanto, tendo em vista que a incidência da anencefalia no país é uma das mais acentuadas do planeta. Assim sendo, como garantir que as mulheres que pos- suem fetos anencéfalos em seus ventres tenham sua integridade física e moral respeitadas? Como garantir que as clínicas e hospitais públicos estarão aptos a realizarem tal acompanhamento evolvendo ou não a interrupção da gravidez? Uma vez que a decisão fora tomada pelo judiciário e não pelo legislativo, é possível que o Estado não possua meios para arcar com as despesas oriundas de tal medida? Pode o ente estatal ser responsabilizado no caso de má prestação do serviço destinado às mulheres e seus familiares nessa triste situação? É diante de tais questionamentos que a presente pesquisa se fundamenta e será através do método indutivo-dedutivo que se almeja analisar possíveis violações de direitos oriundas da citada decisão do Supremo Tribunal Federal.

\section{PALAVRAS-CHAVE}

Interrupção de gestação; dignidade humana; feto anencéfalo; decisão do Supremo Tribunal Federal. 


\section{ABSTRACT}

Brazil is the fourth country in the world in cases of anencephalic fetuses, which meant that the question came up the highest body of the Brazilian judiciary and on April 12, 2012 it was decided that the pregnant woman has the freedom to interrupt the pregnancy or not. This decision proves innovative and came to heal old issues of infringement relating to the dignity of women. However, such a measure could lead to serious problems, given that the intervention of the judiciary act of executive power may cause violation of rights, since the Government will not always have the means to provide medical and psychological treatments pregnant women before, during and after the termination of pregnancy. It is worth noting that not all health centers will be able to perform the termination of pregnancy of an anencephalic fetus nor will there be qualified to do so, given that the incidence of anencephaly in the country is one of the highest in the world. Therefore, how to ensure that women have an anencephalic fetus in their wombs have their physical and moral integrity respected? How to ensure that clinics and public hospitals will be able to carry out such monitoring evolving or not termination of pregnancy? Once the decision was taken by the judiciary and not the legislature, it is possible that the state has no means to bear the expenses arising from such action? The state entity may be held liable in case of poor service provision for women and their families in this sad situation? It is faced with such questions that this research is based and will be through the inductive-deductive method that aims to examine possible violations of rights arising from the said decision of the Supreme Court.

\section{KEYWORDS}

Interruption of Pregnancy. Human Dignity. Anencephalic Fetus. Decision of the Supreme Court.

\section{RESUMEN}

Brasil es el cuarto país del mundo en la estadística de fetos con anencefalia, lo que hizo despertar al máximo órgano del poder judicial brasileño y el día 12 de abril de 2012 y se decidió que la mujer embarazada tiene la libertad de dejar o no seguir su embarazo. Esta decisión resulta innovadora y vino a sanar viejas cuestiones de infracción relativos a la dignidad de la mujer. Sin embargo, esta medida podría conducir a serios problemas, ya que la intervención de la Ley de la Judicatura del Poder Ejecutivo puede causar violación de los derechos, ya que el Gobierno no siempre dispone de los medios para proporcionar tratamiento médico y psicológico a las mujeres embarazadas antes, durante y después de la interrupción del embarazo. Merece la pena señalar, que no todos los centros de salud están equipados para llevar a cabo la interrupción del embarazo de un feto donde se observó la anencefalia, teniendo en cuenta que la incidencia de anormalidad en el país es una de las más altas del mundo. Así siendo, ¿cómo garantizar que las mujeres que tengan un feto con ese problema en sus vientres, sean respetadas en su integridad física y moral? ¿Cómo garantizar que las clínicas y hospitales públicos puedan llevar a cabo esos controles en evolución, o no en la interrupción del embarazo? Una vez que la decisión fue tomada por el Poder Judicial y no por el Poder Legislativo, ¿es posible que el Estado no tenga medios para sufragar los gastos resultantes de estos actos? ¿La entidad estatal podrá ser considerada responsable en caso de prestación de servicios deficiente para las mujeres y sus familias en esta triste situación? Y delante de tales cuestionamientos en que se fundamenta la presente investigación, se puede decir que todas esas preguntas se basan en el método inductivo-deductivo, que tiene como objetivo examinar las posibles violaciones de los derechos derivados de dicha decisión de la Corte Suprema.

\section{PALABRAS CLAVE}

Interrupción del Embarazo. La Dignidad Humana. Feto con anencefalia. Decisión de la Corte Suprema. 


\section{INTRODUÇ̃̃̃O}

\begin{abstract}
"A vida é dom de Deus, e deve, portanto, ser tutelada pelas leis, protegida pelas religiões, defendida pelas ciências particulares e apoiada por toda a sociedade". (Galvão, 2004, p. 11).
\end{abstract}

Depois de muita discussão e análise, o Supremo Tribunal Federal decidiu no dia 12 de abril de 2012, por oito votos a dois, que não é crime a interrupção de gestação de fetos anencéfalos.

A maior parte dos ministros entendeu que o Sistema Único de Saúde possui meios para constatar tal anomalia e, após o diagnóstico, caberá à mulher decidir se quer continuar a gestação ou interrompê-la, tendo em vista que em tais circunstâncias o feto não possui a menor chance de sobreviver, não havendo nenhuma expectativa de direitos.

Entretanto, até que ponto o Supremo Tribunal Federal possui autonomia para dirimir sobre tal assunto,

\section{FETO ANENCÉFALO E 0 DIAGNÓSTICO}

Recentemente o Supremo Tribunal Federal decidiu por maioria de votos que a gestante possui o livre arbítrio para continuar com a gestação de feto anencéfalo ou interrompê-la. Para tanto, deve ser esclarecida e o diagnóstico da anencefalia necessita ter sido realizado por profissionais devidamente habilitados.

Tal anomalia é bastante comum, sendo que nesses casos, conforme os dizeres de Diniz, (2010, p. 353), o feto detém:

[...] malformação congênita, não possui uma parte do sistema nervoso central, ou melhor, faltam-lhe os hemisférios cerebrais e tem uma parcela do tronco encefálico (bulbo raquidiano, ponte e pedúnculos cerebrais). Como os centros de respiração e circulação tendo em vista que, para efetivá-lo, serão necessários gastos públicos com profissionais da saúde qualificados, hospitais próprios para receberem gestantes que optem pela interrupção da gestação, entre outros?

O ente estatal poderá alegar falta de recursos para efetivar tais direitos? Como garantir que a gestante será atendida de forma eficaz e terá seus direitos respeitados?

As discussões acerca de tais medidas são muitas e estão longe de serem resolvidas, uma vez que o Brasil, por ser um Estado Democrático de Direito, preza pela separação dos poderes legislativo, executivo e judiciário, assim sendo, é preciso muito cuidado ao interferir em tais assuntos no intuito de que não ocorram ilegalidade e intromissão de um poder na seara dos demais. sanguínea situam-se no bulbo raquidiano, mantém suas funções vitais; logo o anencéfalo poderá nascer com vida, vindo a falecer horas, dias ou semanas depois. Por tal motivo, há quem ache que é um banco ou repositório de órgãos e tecidos para fins de transplantes em crianças, pelo seu tamanho e por não causar rejeição.

Assim, no caso de fetos anencéfalos, ocorre a falta do encéfalo e do crânio, sendo impossível a manutenção da vida extrauterina. Para o ministro Marco Aurélio (STF), "o anencéfalo, tal qual o morto cerebral, não tem atividade cortical” (2012, p. 46).

Diz Maluf (2010, p. 122) que tal defeito ocorre entre o $16^{\circ}$ e $26^{\circ}$ dia após a concepção. 
Aponta Diniz (2010, p. 55) que a citada anomalia pode ocorrer devido a alguma mutação genética. Existem ainda "[...] outros fatores, como a falta de ácido fólico (uma vitamina do complexo B) no organismo. Estão no grupo de risco mães com diabetes mellitus e que trabalham com agrotóxicos". O consumo de ácido fólico um mês antes da gravidez e nos três primeiros meses de gestação reduz a incidência de fetos anencéfalos. Tal elemento pode ser encontrado em comprimidos e vegetais com folhas verdes, como o espinafre e o brócolis.

A medicina e as ciências da saúde atualmente possuem amplos poderes para diagnosticar com plena certeza casos de fetos anencéfalos, além de outras três mil patologias congênitas, através de ultrassonografia e o exame de alfafetoproteína ${ }^{1}$, conforme ressalta Diniz (2010, p. 478).

Assim, nos dizeres de Maluf (2010, p. 123),

[...] o feto portador de anencefalia apresenta uma característica única e inconfundível: não possui os ossos do crânio (a partir da parte superior da sobrancelha não há osso algum), razão pela qual sua cabeça não possui o formato arredondado. É por esse motivo que comumente o feto portador dessa anomalia é chamado de feto-rã.

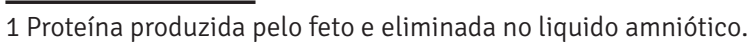

Conforme voto do ministro Marco Aurélio de Mello (2012, p. 1), relator da Ação de Descumprimento de Preceito Fundamental (ADPF) de número 54, tal medida se fez necessária tendo em vista que "o Brasil é o quarto País no mundo em casos de fetos anencéfalos”, uma vez que fica atrás apenas de Chile, México e Paraguai, sendo que a ocorrência de tal anomalia é de aproximadamente um para cada mil nascimentos.

Assim, o ministro entende ser totalmente legal a intervenção do judiciário na seara legislativa, uma vez que a medida veio a suprir violações de direitos.

O ministro Luiz Fux (2012, p. 1) acredita ser essencial tal medida, uma vez que o Brasil possui um alto índice de fetos anencéfalos, sendo que "as autorizações judiciais para a interrupção da gravidez em situações semelhantes se multiplicaram em todo o País, exigindo deste Pretório Excelso uma manifestação definitiva".

Assim sendo, foi de extrema relevância a decisão tomada pela maioria dos ministros do Supremo Tribunal Federal, no intuito de garantir maior dignidade e menor sofrimento às mulheres que carregam em seus ventres fetos sem a menor chance de sobreviver fora do útero.

\section{ABORTO NA LEI BRASILEIRA}

Conforme ditames do Código Penal Brasileiro, o aborto provocado pela gestante ou com o seu consentimento é crime tipificado no artigo 124, cuja pena é de detenção e varia de um a três anos. 0 aborto cometido sem o consentimento da gestante também é crime, cabendo para o autor do delito reclusão de três a 10 anos, conforme o artigo 125 do citado dispositivo. Já o artigo 126 tipifica o aborto provocado por terceiro com o consentimento da gestante, cuja pena

de reclusão varia de um a quatro anos.

Caso a gestante fique com sequelas ou venha a falecer devido à prática do aborto ou dos meios utilizados, a pena será aumentada em um terço no primeiro caso e dobrada no segundo.

Entretanto, a lei brasileira concede algumas exceções quanto à tipificação do aborto, previstas no arti- 
go 128 do Código Penal:

Art. 128. Não se pune o aborto praticado por médico: Se não há outro meio para salvar a vida da gestante; Se a gravidez resulta de estupro e o aborto é precedido de consentimento da gestante ou, quando incapaz, de seu representante legal.

Para o ministro Lewandowski (2012, p. 5), que votou contra a interrupção de gravidez de feto anencéfalo, "[...] o legislador, de modo explícito e deliberado, não afastou a punibilidade da interrupção da gravidez nessas situações. Quer dizer, considerou penalmente imputável o abortamento induzido de um feto mal formado".

Entretanto, para a maioria dos ministros do Supremo Tribunal Federal, a anencefalia é uma anomalia onde o feto jamais se tornará pessoa, uma vez que não há vida em potencial, assim o fato de respirar e ter batimentos cardíacos não alteram a situação, como também não alteram nos diagnósticos de morte cerebral (MELLO, 2012, p. 50-1).

O ministro Luiz Fux aponta ainda que são altos os perigos para a saúde da mulher em uma gravidez de feto acometido pela anencefalia, havendo, inclusive, risco de vida, razão pela qual, se esse for o desejo, deve-se conferir possibilidade de interrupção da gestação, à luz do princípio da proporcionalidade.

Com a decisão do Supremo Tribunal Federal, a possibilidade de interromper a gravidez se origina da certeza de ausência de vida, uma vez que o feto anencéfalo não possui expectativa nenhuma de vida extrauterina, assim, se é aceito no País o aborto em caso de risco de vida para a mulher e estupro, nos quais o feto, em tese é saudável, porque obrigar a mãe a gestar um feto que não possui esperança nenhuma de cura, colocando em risco a sua própria saúde?

No caso de feto anencéfalo, conforme dito, não há crime de aborto, uma vez que não há expectativa de vida, e o casal poderá se recuperar da dor e sofrimen- to e ter outros filhos, pois, conforme os dizeres de Diniz $(2010,491)$, "[...] a chance do casal de ter um outro [filho] normal será de 90 a 98\%".

De acordo com o ministro do Supremo Tribunal Federal, Marco Aurélio de Mello (2012, p. 60) o “[...] feto anencéfalo, mesmo que biologicamente vivo, porque feito de células e tecidos vivos, é juridicamente morto, não gozando de proteção jurídica e, acrescento, principalmente de proteção jurídico-penal", assim sendo, interromper a gravidez de feto anencéfalo não configura crime, tendo em vista ser conduta atípica, uma vez que não há vida em potencial, muito menos personalidade jurídica.

Conforme os dizeres do ministro Luiz Fux (2012, p. 13):

[...] o direito penal atua como expressão do dever de proteção do Estado aos bens jurídicos constitucionalmente relevantes, como a vida, a dignidade, a integridade das pessoas e a propriedade. A tipificação de delitos e a atribuição de penas também são mecanismos de proteção a direitos fundamentais.

Se não há crime, não existem motivos para que a interrupção de gravidez em tais casos seja considerada errada, cabendo única e exclusivamente à gestante, com apoio de sua família, decidir ir adiante com a gravidez ou não e, caso decida pela interrupção, que possa fazê-lo sem enfrentar meses de demora diante da justiça brasileira.

Frise-se que o Estado deve conceder esse direito à mulher em decidir ir adiante ou interromper a gravidez, nos dizeres do ministro do Supremo Tribunal Federal Marco Aurélio de Mello (2012, p. 60), não há que se argumentar em colisão entre a dignidade da mulher e a do feto, tendo em vista que "[...] não há ninguém por vir, não há viabilidade de vida" e continuar com a gestação pode ocasionar sofrimento tão acentuado que poderá ser equiparado à tortura, vedada na Carta Constitucional (art. $\left.5^{\circ}, \mathrm{III}\right)$. 
Uma vez que existam divergências entre o casal acerca da interrupção da gravidez, entende-se que deve ser priorizada a decisão da mulher, tendo em vista que é a sua vida e a sua dignidade que podem correr perigo.

\section{SAÚDE PÚBLICA E A RESPONSABILIDADE CIVIL}

A efetivação da saúde é de responsabilidade do ente estatal, que deverá fornecê-la através de políticas públicas, bem como de responsabilidade de toda a sociedade e de cada indivíduo.

Caso não haja suporte adequado para realizar a interrupção da gravidez, seja pela péssima condição dos hospitais, seja pela demora no atendimento, o ente estatal poderá ser responsabilizado pelo sofrimento ocasionado na gestante? Caberiam danos morais e materiais?

Figueiredo (2007, p. 93) aponta que “[...] ainda no que tange à eficácia, cumpre salientar que o direito à saúde se dirige também aos particulares, de modo que o dever de efetivá-lo não compete exclusivamente ao Estado". O Sistema Único de Saúde, previsto na Constituição brasileira de 1988 e implementado pela Lei 8.080/90, é a principal política pública com vista à garantia do direito constitucional à saúde.

Impasses jurídicos muitas vezes apresentam grandes dificuldades para serem sanados, quando o tema é direito fundamental à saúde não é diferente, cabendo ao jurista atuar de forma sensata e o mais eficaz possível.

Ressalte-se que “[...] a responsabilidade do Estado poderá ocorrer se, aliada à força maior, ocorrer omissão do Poder Público na realização de um serviço" (DI PIETRO, 2008, p. 616). Entretanto nesses casos a
Assim sendo, mister se faz regulamentar, com a alteração do Código Penal a possibilidade da gestante escolher se irá interromper ou não a gravidez de feto anencéfalo, cabendo tal função ao poder legislativo.

responsabilidade deixa de ser objetiva e passa a ser subjetiva, visto que é oriunda de mau funcionamento do serviço público, a omissão na prestação do serviço público tem levado à aplicação da teoria da culpa do serviço público, que se trata de culpa anônima, não individualizada; o dano não decorre através da atuação de agente público, mas de omissão do poder público.

Para Pozzoli (2011, p. 227), um dos maiores aliados na luta pela efetivação de direitos e o respeito da dignidade humana é o Poder Judiciário que "junto com a sociedade, busca construir novas estratégias de efetividade dos direitos humanos, trilhando cobranças para que se realizem políticas públicas na área da cidadania”.

A decisão inédita do Supremo Tribunal Federal trouxe benefícios para a sociedade, uma vez que a gestante de feto anencéfalo, hoje, tem a faculdade de decidir de acordo com seu entendimento.

Nos dizeres de Martin (2011, p. 72):

Embora seja preferível a não intervenção do Poder Judiciário nas políticas públicas, diante da omissão do Estado, será o Judiciário obrigatoriamente instado a se manifestar, necessitando analisar o caso com minúcia e atenção, pois, conforme a decisão do STF, não é qualquer alegação de ausência de recursos orçamentários que inviabilizará a efetivação dos direitos sociais, sob pena de reconhecer-se que o orçamento sobrepõe-se aos direitos fundamentais o que, em ver- 
dade, se mostra o contrário, os direitos fundamentais encontram-se, na maioria das vezes, acima da existência de recursos materiais.

Assim, conclui-se que a responsabilidade do Estado somente será objetiva no caso da ação, no que cabe a omissão, a responsabilidade seria sempre subjetiva, visto que em casos de omissão, se faz necessário averiguar primeiramente se o fato causador do dano era previsível e se o ente administrativo dispunha de meios para evitá-lo.

\section{QUANDO 0 JUDICIÁRIO DEVE AGIR?}

A separação dos três poderes trazida no texto constitucional deve ser respeitada, entretanto, é inadmissível que se permita violações constantes de direitos.

Um dos maiores desafios de um Estado Social de Direito é conciliar o bem-estar social com as emergentes necessidades da sociedade, que se alteram cotidianamente (MARTINS et al, 2011, p. 67).

Tendo em vista que os órgãos judiciários jamais poderão deixar uma questão sem solução, nem sempre possuem recursos para realmente avaliar os casos que chegam e diante da ausência de leis especificas, podem ser levados a cometerem graves erros, uma vez que "ao estabelecer a inafastabilidade do controle jurisdicional, a Constituição não especificou quais matérias deveriam ser apreciadas ou não pelos Tribunais" (MACHADO et al, 2011, p. 105).

\section{LEl 8080/90 [SUS]}

0 artigo $4^{\circ}$, da Lei do Sistema Único de Saúde (SUS), assim o define como sendo um conjunto de ações e serviços de saúde, que são prestados por seus órgãos e instituições públicas, sejam elas federais, estaduais municipais, da administração direta e indireta e das fundações mantidas pelo Poder Público, podendo a iniciativa privada atuar em caráter supletivo.

As atuais normas que regem o SUS muito se diferenciam das utilizadas por décadas atrás por inúmeras normas, entretanto, ainda nos dias de hoje não foi possível atender as reais necessidades da população (MARIN et al, 2011, p. 195). 
Para Figueiredo (2007, p. 97), “[...] o SUS é um sistema público e nacional, baseado no princípio da universalidade, a indicar que a assistência à saúde deve atender a toda população".

A partir da Emenda Constitucional n. 29 passou a ser obrigatório um mínimo de recursos para o custeio das ações e serviços de saúde vindos da União, estados e municípios, caso esse mínimo exigido por lei não seja respeitado, pode haver intervenção da União e/ou dos Estados nos municípios.

A fiscalização e o total cumprimento da lei no que cabe à saúde são de extrema importância para o bom funcionamento do SUS e tornar menos gravoso a situação de cerca de 130 milhões de brasileiros, que dependem exclusivamente deste sistema (RAEFFRAY, 2005, p. 294).

O grande problema no País é que ainda não é dada a mesma importância à saúde, previdência e assistência social, conforme os ditames da Carta normativa de 1988. A saúde só se desenvolverá como todos gostariam a partir do momento que for tratada como algo coletivo, de uso de todos, não se trata apenas de ter ou não saúde, trata-se de qualidade de vida a todos os cidadãos, unindo todos os ramos da sociedade.

\section{É através da lei que num Estado Democrático de Direito será possível garantir um mínimo existencial a todos os indivíduos. É a Constituição sendo marco em favor da justiça social, no Brasil ainda há um longo caminho a percorrer para que de fato as políticas públicas se efetivem, entretanto, com os ditames da carta de 1988 os princípios a serem segui- dos já foram lançados (STRECK, 2002, p. 85 e 86).}

O direito à saúde é ponto crucial para a vida e a dignidade humana, posto isso, assim deve ser tratado, não podendo ser medidos esforços para atingi-lo, portanto, mister se faz que hajam políticas públicas a fim de capacitar profissionais, melhorar estruturas hospitalares que necessitem no intuito de melhor atender as gestantes de fetos anencéfalos, tenham optado pela interrupção ou não.

\section{CONSIDERAÇÕES FINAIS}

O Supremo Tribunal Federal tem contribuído de forma ímpar para a efetivação de direitos, o ano de 2012 está sendo marcado por decisões inéditas, como o caso tratado no presente estudo.

Uma vez que o judiciário tem sido solicitado a se manifestar, os julgamentos têm sido cuidadosamente analisados, uma vez que podem ocasionar ilegalidades.

Com tal decisão, que pôs fim a dezenas de clamores, possibilitando que a gestante, por livre e espontânea vontade, possa decidir ir adiante ou interromper a gestação de feto anencéfalo.

Nesse ínterim, o ente estatal poderá ser responsabilizado, caso deixe, de forma omissa, a propiciar à gestante meios para efetuar a interrupção da gestação ou, caso decida continuar gestando, meios para que não perca sua integridade física e psíquica.

O Estado arcará com os danos, existindo ou não dolo. Contudo, apesar de ser responsabilidade do Estado garantir assistência gratuita e universal à saúde, os indivíduos, como membros dessa sociedade tem o 
dever de cuidar não só dos seus direitos, mas do direito de todos.

Assim sendo, embora a decisão que possibilitou a interrupção de fetos anencéfalos tenha sido proferida pelo poder judiciário, após exaustiva análise acerca da possibilidade jurídica e médica de tal medida e análise da possibilidade do ente público efetivar tal direito, caberá agora ao poder legislativo melhor regulamentá-lo, em prol de toda a sociedade, em espe- cial das mulheres que já passaram ou passarão pela dor de estarem gestando fetos sem vida.

0 jurista e o profissional do direito de forma geral que irá atuar no século XXI têm, acima de tudo, um papel decisivo diante da sociedade, pois ou este profissional esquece dos preceitos aprendidos nas salas de aula e será mais um em meio a multidão, ou luta pelo que acreditou um dia, torna as leis e as jurisprudências mais eficazes e faz toda a diferença.

\section{REFERÊNCIAS}

AMARAL, Sérgio Tibiriçá et al. Efetivação judicial das normas constitucionais sociais não regulamentadas. In: Direitos sociais: uma abordagem quanto à (in)efetividade desses direitos - a Constituição Federal e suas previsões sociais. Dirceu Pereira Siqueira e Teófilo Marcelo de Arêa Leão Junior (organizadores). 1 ed. Birigui/SP: Boreal, 2011. p. 330-349.

BRASIL. Lei n. 8.080, de 19 de setembro de 1990. Dispõe sobre as condições para a promoção, proteção e recuperação da Saúde, a organização e o funcionamento dos serviços correspondentes e dá outras providências, [on-line], Brasília, 1990. Disponível em: http://www6.senado.gov.br/legislacao/ListaPublicacoes. action?id=134238, acessado dia 10.07.2013.

BRASIL. Código Civil: lei n 10.406, de 10 de janeiro de 2002. Vade mecum compacto: Obra Coletiva. 7. ed. atual. e ampl. São Paulo: Saraiva, 2012.

BRASIL. Código Penal: Decreto-lei no 2.848, de 7 de dezembro de 1940. Vade mecum compacto: Obra Coletiva. 7. ed. atual. e ampl. São Paulo: Saraiva, 2012.

BRASIL. Constituição Federal: de 05 de outubro de 1988. Vade mecum compacto: Obra Coletiva. 7. ed. atual. e ampl. São Paulo: Saraiva, 2012.

BRASIL. STF: a Constituição e o Supremo. Disponível em: http://www.4shared.com/get/237061511/ ee10e002/A_Constituio_e_o_Supremo.html;jsessionid=B4E6971EFCF38C96350B9F9B135DCDFE.dc158, acessado em 09.07.2013.

DINIZ, Maria Helena. 0 estado atual do biodireito. 7. ed. rev. aum. e atual. São Paulo: 2010.

DI PIETRO, Maria Sylvia Zanella. Direito administrativo. 21 ed. São Paulo: Atlas, 2008. 
FIGUEIREDO, Mariana Filchtiner. Direito fundamental à saúde: parâmetros para sua eficácia e efetividade. Porto Alegre: Livraria do Advogado, 2007.

MACHADO, Edinilson Donisete et al. 0 amicus curiae no controle judicial de políticas públicas e a "reserva de substância". In: Direitos sociais: uma abordagem quanto à (in)efetividade desses direitos - a Constituição Federal e suas previsões sociais. Dirceu Pereira Siqueira e Teófilo Marcelo de Arêa Leão Junior (organizadores). 1 ed. Birigui/SP: Boreal, 2011. p. 100-112.

MALUF, Adriana Caldas do Rego Freitas Dabus. Curso de bioética e biodireito. São Paulo: Atlas, 2010.

MARTINS, Andréia Garcia et al. A quimera dos direitos fundamentais: análise da eficácia dos direitos sociais, à luz de sua justiciabilidade. Alan et al. Saúde como garantia fundamental: uma perspectiva da evolução constitucional e histórica das políticas públicas. In: Direitos sociais: uma abordagem quanto à (in)efetividade desses direitos - a Constituição Federal e suas previsões sociais. Dirceu Pereira Siqueira e Teófilo Marcelo de Arêa Leão Junior (organizadores). 1 ed. Birigui/SP: Boreal, 2011. p. 60-81.

POZZOLI, Lafayette et al. Dignidade da pessoa humana e ética social: a função promocional do direito. In: Direitos sociais: uma abordagem quanto à (in)efetividade desses direitos - a Constituição Federal e suas previsões sociais. Dirceu Pereira Siqueira e Teófilo Marcelo de Arêa Leão Junior (organizadores). 1 ed. Birigui/SP: Boreal, 2011. p. 217-234.

RAEffraY, Ana Paula Oriola de. Direito da saúde: de acordo com a Constituição Federal. 1 ed. São Paulo: Quartier Latin, 2005.

STRECK, Lênion Luiz. Jurisdição constitucional e hermenêutica: uma nova crítica do direito. Porto Alegre: Livraria do advogado, 2002. 
Recebido em: 3 de agosto de 2013 Avaliado em: 10 de agosto de 2013 Aceito em: 11 de agosto de 2013
1 Mestranda em Direito no Centro Universitário Eurípedes de Marília/SP - Univem, Professora no ITL Educação Profissional, área de Direito, Três Lagoas/MS-Brasil. e-mail: karoll_kamargo@hotmail.com 